\title{
Residual Stress-Affected Diffusion during Plasma Nitriding of Tool Steels
}

\author{
THOMAS K. HIRSCH, ALEXANDRE DA S. ROCHA, FABIANO D. RAMOS, \\ and TELMO R. STROHAECKER
}

\begin{abstract}
Plasma nitriding of tool materials is common practice to improve the wear resistance and lifetime of tools. Machining-induced compressive residual stresses in shallow layers of some tenths of microns are observed accompanied by other characteristic properties of machined surfaces in these high-strength materials. After plasma nitriding of M2 high-speed steel, previously induced compressive residual stresses remain stable and the depth of diffusion layers decreases with increasing compressive residual stresses. This article reports investigations of plasma nitrided samples with different levels of residual stresses induced prior to the nitriding process. For comparison, experiments with bending load stresses during plasma nitriding have also been carried out. The plasma nitriding treatment was performed at constant temperature of $500{ }^{\circ} \mathrm{C}$ with a gas mixture of $5 \mathrm{vol} \mathrm{pct} \mathrm{N}_{2}$ in hydrogen. Nitriding time was varied from 30 to 120 minutes. All samples were characterized before and after plasma nitriding concerning microstructure, roughness, microhardness, chemical composition, and residual stress states. Experimental results are compared with analytical calculations on (residual) stress effects in diffusion and show a clear effect of residual and load stresses in the diffusion of nitrogen in a high-strength M2 tool steel.
\end{abstract}

\section{INTRODUCTION}

NITRIDING is a common surface treatment practice for tool steels. Plasma nitriding treatments can be made below the tempering temperature of these steels. Surface bombardment with ions and neutral particles additionally is able to destroy surface oxide depassivation of higher (chromium) alloyed steels. ${ }^{[1,2,3]} \mathrm{In}$ typical applications of plasma nitriding or plasma nitrocarburizing, 4- to $15-\mu \mathrm{m}$ thick white layers of iron-(carbo)-nitrides and diffusion layers of $50 \mu \mathrm{m}$ to $0.4 \mathrm{~mm}$ thickness are formed, ${ }^{[4-8]}$ depending on nitriding parameters and material. Recent work indicated that it may be beneficial for tool steels to be plasma nitrided without white layer. ${ }^{[5,6]}$ White layer and diffusion layer properties affect wear in different ways depending on the tribological system under consideration. A significant formation of main alloying element (carbo)-nitrides results in the wellknown hardness increase of the diffusion layer. Depending on the amount of dissolved nitrogen in the matrix, the number and distribution of these precipitates differ. Differences in the specific volume of precipitates and matrix and finally differences in the thermal expansion coefficients then are closely related to the generation of micro- and macroresidual stresses. ${ }^{[9-12]}$ Earlier work has indicated a correlation between properties of nitride layers and wear of drills as a function of surface states prior to nitriding. ${ }^{[6]}$ Surface states of tools after machining generally are characterized by surface topography, surface layer residual stress states, and work hardening or softening.

Tool steels with their high hot yield strength will not show any relaxation of machining-induced residual stresses below the applied tempering temperature of the steel. A superimposition of residual stresses caused by the manufacturing of tools

THOMAS K. HIRSCH, Research Director, and ALEXANDRE DA S. ROCHA, Senior Research Scientist, are with the Stiftung Institut fuer Werkstofftechnik, 28359 Bremen, Germany. Contact e-mail: hirsch@iwt. uni-bremen.de FABIANO D. RAMOS, Postgraduate Student, and TELMO R. STROHAECKER, Professor, are with the Universidade Federal do Rio Grande do Sul, Porto Alegre RS 90035-A90, Brazil.

Manuscript submitted December 10, 2003. with nitriding residual stress is to be expected. Although literature for low-strength steels reported an intensified growth of white layers after prior plastic deformation ${ }^{[13,14]}$ and after deep rolling and nitrocarburizing ${ }^{[15]}$ of an unalloyed medium carbon steel no increased thickness of diffusion layers was found, it cannot be excluded that the quantity of precipitated nitrides will be affected by plastic deformation prior to nitriding. The sum of machining-induced residual stress and residual stresses generated during nitriding can exceed the yield strength at elevated temperatures. Residual stresses after plasma nitriding would then be limited to the material's resistance against yielding at nitriding temperature. ${ }^{[10]}$ For high-strength tool steels, effects from grinding-induced compressive residual stresses on the diffusion of nitrogen in the iron matrix, however, cannot be excluded. ${ }^{[16,17]}$ High hydrostatic compressive stresses in lowstrength materials lead to an increase of activation energy for diffusion and thus to a reduction of the diffusion coefficient. ${ }^{[16]}$

To study effects of residual stresses on the diffusion of nitrogen, specimens made from M2 tool steel have been polished and sand blasted to generate different levels of residual stresses. These samples were subjected to plasma nitriding at constant temperature for different times between 30 and 120 minutes. Nitriding parameters were set in such way that no white layer occurred. To ascertain the effects from residual stresses, bending load stresses of different sign have been applied during plasma nitriding. Therefore, in this article, an attempt was made to elucidate effects of residual and load stresses on the diffusion of nitrogen in M2 tool steel. Differences will be verified by metallographic analysis, element depth profiles of nitrogen, and X-ray diffraction residual and load stress measurements. Hydrostatic parts of residual and load stress tensors were calculated and used to theoretically demonstrate changes of nitrogen diffusion in high-strength steels.

\section{MATERIALS}

Chemical composition of the high-speed steel AISI M2 is given in Table I. Sample shape and size were rectangular 
Table I. Chemical Composition of Investigated Material (Ma Pct)

\begin{tabular}{lcccccc}
\hline Material & C & W & Mo & Cr & V & Co \\
\hline AISI M2 & 0.89 & 6.03 & 4.75 & 4.01 & 1.68 & 0.43 \\
\hline
\end{tabular}

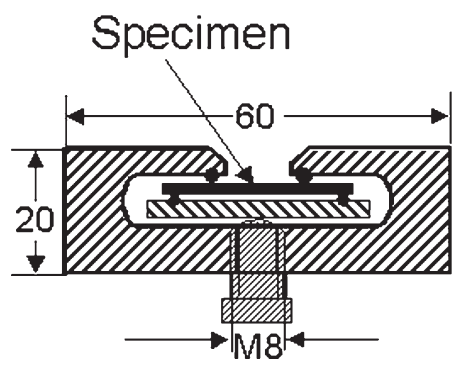

Fig. 1-Bending device for plasmanitriding under applied load (this case: compressive bending stresses in the top layer of the specimen).

with a length of $30 \mathrm{~mm}$ and a width of $12 \mathrm{~mm}$. The sample thickness was $2 \mathrm{~mm}$. This specimen shape was selected in order to apply high amounts of load stresses during plasma nitriding in suitable devices (Figure 1).

\section{EXPERIMENTAL PROCEDURE}

All samples were heat treated according to specifications given for M2 high-speed steel. ${ }^{[18]}$ The last heat-treatment step was a threefold tempering at $560{ }^{\circ} \mathrm{C}$ for 2 hours. After tempering, samples were submitted to different surface treatments. One part of the specimen batch has been ground similar to metallographic preparation, including a final step of polishing with diamond paste of grain size $1 \mu \mathrm{m}$. The second part of the heat-treatment batch was treated with a sand blasting treatment. Parameters were as follows: alumina $\left(\mathrm{Al}_{2} \mathrm{O}_{3}\right)$ shot with a mean grain size of $0.85 \mathrm{~mm}$, an air pressure of $3.5 \mathrm{bar}$, a treatment time of 30 seconds, and 90 deg inclination of the nozzle. Compared to polished samples thus produced, surface roughness proved to be unfavorable for further analysis in hardness testing and glow discharge optical emission spectroscopy (GDOES). To ascertain similar surface states for all specimens, sand-blasted samples were slightly polished to remove any sand-blasting-induced roughness. Polished samples were taken for bending tests. Load stresses have been applied up to $+700 \mathrm{MPa}$ tensile stress and up to $-1000 \mathrm{MPa}$ compressive stress in a simple bending device, presented in Figure 1. In the load case, shown in Figure 1, compressive bending stresses are loaded in the upper surface by tightening the screw. The top opening allowed access for X-ray diffraction analysis of nitrided layers in loaded conditions. X-ray diffraction analysis was also used to measure the sum of load and residual stresses prior to nitriding, and residual stresses are known from measurements of unloaded specimens. So far, load stresses could be determined reasonably accurately after each step of loading. By changing the top and bottom bearing positions of the bending device, tensile stresses could be applied. After plasma nitriding, the sum of load stresses and nitriding residual stresses were checked again by X-ray diffraction. Again, comparison with unloaded conditions gave information about relaxation of load stresses during plasma
Table II. Overview of Investigated Sample Modifications and Nitriding Times

\begin{tabular}{lccc}
\hline Nitriding time (min) & 30 & 60 & 120 \\
\hline AISI M2, polished & $\mathrm{x}$ & $\mathrm{x}$ & $\mathrm{x}$ \\
M2, sandblasted + polished & $\mathrm{x}$ & $\mathrm{x}$ & $\mathrm{x}$ \\
M2, polished + load stresses & - & $\mathrm{x}$ & - \\
\hline
\end{tabular}

nitriding at $500{ }^{\circ} \mathrm{C}$. No major relaxation of load stresses could be observed at any time.

The plasma nitriding treatments were executed in a laboratory plant without an additional heating system. A gas composition of $5 \mathrm{vol}$ pct $\mathrm{N}_{2}$ in $\mathrm{H}_{2}$, a pressure of $5 \mathrm{mbar}$, and nitriding times of 30,60, and 120 minutes were selected (for details of the equipment, see References 5 and 19). A constant nitriding temperature of $500{ }^{\circ} \mathrm{C}$ could be recorded after 8 to 10 minutes heating-up time with the plasma. The nitriding batch of eight samples was arranged symmetrically on a circular sample holder. Four bending devices with loaded specimens formed another run of plasma nitriding. An independent temperature control was provided by thermocouples inserted into a separate sample. Table II gives an overview of the investigated surface states.

Depth profiles of chemical composition were determined by means of GDOES. ${ }^{[20,21]}$ Measuring conditions of X-ray phase analysis were: $\mathrm{Cr} K_{\alpha}$ radiation with a primary aperture of $2.4 \mathrm{~mm}$ in diameter, a measuring range of $50 \mathrm{deg}<2 \theta<162 \mathrm{deg}$ with a step size of $0.05 \mathrm{deg}$, and a step time of 20 seconds. Residual stress measurements were executed with a $\psi$-diffractometer using $\mathrm{Cr} K_{\alpha}$ radiation on $\{211\}$-lattice planes of $\alpha$-iron. From residual strains of different angles $\psi$, residual stresses were computed according to the $\sin ^{2} \psi$ procedure ${ }^{[22]}$ with macroscopic elastic constants of $E=210,000 \mathrm{MPa}$ and $v=0.28$. Depth profiles of residual stresses were obtained from electrochemical surface layer removal. Corrections of measured residual stresses regarding nitrogen gradients were done according to the procedure in Reference 23. Additional correction of residual stresses after layer removal was not performed.

\section{RESULTS}

First, the surface states of polished and sand-blasted samples were characterized by measurements of surface topography and residual stresses. The following metallographic results of plasma nitriding treatments are presented, supplemented by the depth profiles of the elements nitrogen and carbon.

Residual stress depth profiles are plotted in Figure 2. These results prove that two surface layers with almost the same surface topography (Table III) but totally different residual stress distributions have been generated. Only a thin $10-\mu$ m-thick layer of compressive residual stresses can be attributed to polished samples. Surface values of residual stresses do not exceed $-130 \mathrm{MPa}$. As expected, for the sand-blasted samples, an approximately $60-\mu \mathrm{m}$-thick layer with compressive residual stresses is observed. Surface residual stresses are as high as -1600 MPa. In Figure 2, additionally, one load stress distribution for a compressive bending stress of $1200 \mathrm{MPa}$ at the surface is displayed. As can be seen, substantially thicker layers with compressive (or tensile) load stresses occur accord- 
Table III. Surface Values Prior to Nitriding

\begin{tabular}{lcccc}
\hline Condition & $\begin{array}{c}R_{z} \\
(\mu \mathrm{m})\end{array}$ & $\begin{array}{c}\sigma_{R S, 0} \\
(\mathrm{MPa})\end{array}$ & $\begin{array}{c}\mathrm{FWHM}_{\mathrm{o}} \\
(\mathrm{Deg})\end{array}$ & $\mathrm{HV} 1$ \\
\hline Polished & 0.24 & -127 & 5.8 & 860 \\
Sand Blasted + Polished & 0.10 & -1580 & 5.8 & 870 \\
\hline
\end{tabular}

FWHM-full-width at half-maximum.

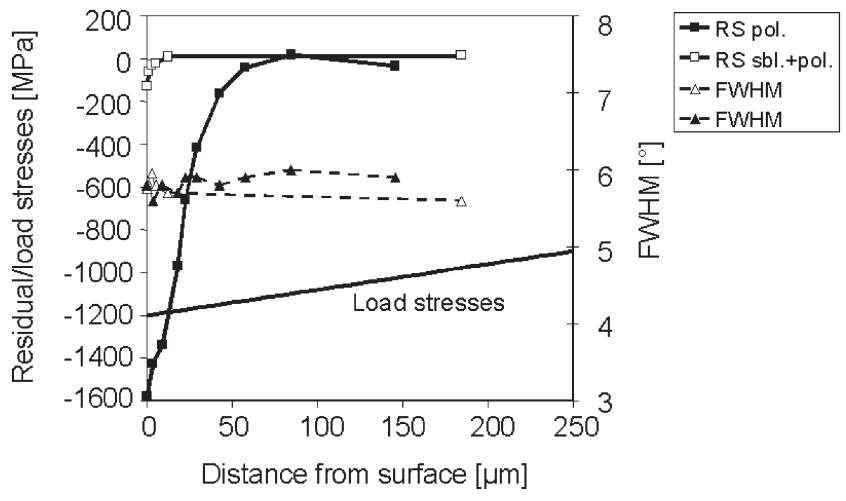

Fig. 2-Depth profiles of residual and load stresses, respectively, as well as FWHM of X-ray diffraction lines prior to nitriding (sbl. = sand-blasted, pol. = polished)

Table IV. Surface Layer Hardness and Nitriding Depth from Hardness Distributions

\begin{tabular}{lcc}
\hline Condition & $\begin{array}{c}\text { Surface Layer } \\
\text { Hardness HV0.025 }\end{array}$ & $\begin{array}{c}\text { Nitriding } \\
\text { Depth }(\mu \mathrm{m})\end{array}$ \\
\hline Polished, 30 min & 1380 & 28 \\
Polished, 60 min & 1206 & 61 \\
Polished, 120 min & 1640 & 108 \\
Sand-blasted, 30 min & 1380 & 16 \\
Sand-blasted, 60 min & 1380 & 30 \\
Sand-blasted, 120 min & 1250 & 92 \\
\hline
\end{tabular}

ing to the zero crossing in 1-mm depth, if we compare the load stress distribution with residual stress distributions.

After plasma nitriding surface layer hardness and nitriding depth are given in Table IV. For each of the nitrided specimens, a value of $50 \mathrm{HV} 0.025$ was added to the core hardness, and the nitriding depth was estimated from hardness distributions at the given hardness value. Table IV demonstrates that shallow diffusion layers occur as expected for a M2 tool steel. Depth differences can be observed to be due to the different surface layer properties prior to nitriding. Surface layer hardness to be determined from metallographic cross sections shows considerable experimental scatter due to the low load in Vickers hardness tests and effects from residual stresses. The mean values of surface layer hardness are about 400 HV0.025 above the core hardness.

Metallographic cross sections in Figure 3 demonstrate the observed differences in more detail for 120 minutes nitriding time. Surface layers of polished samples with low residual stress values give substantially thicker diffusion layers. Similar results for 60 minutes nitriding time occur if tensile or compressive load stresses have been applied (Figure 4).
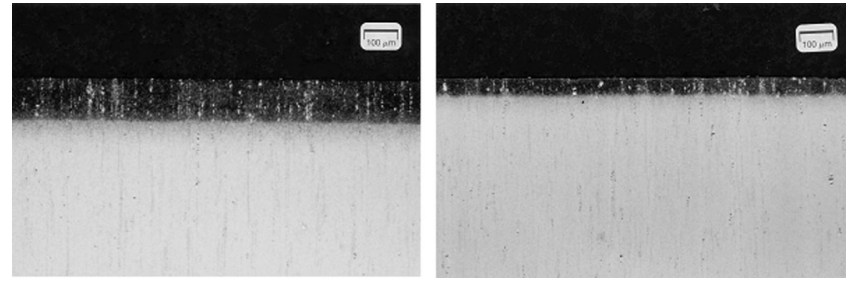

Fig. 3-Metallographic cross sections after 120-min nitriding time. Comparison of the different surface states: polished (left), sand-blasted (right). ${ }^{[32]}$
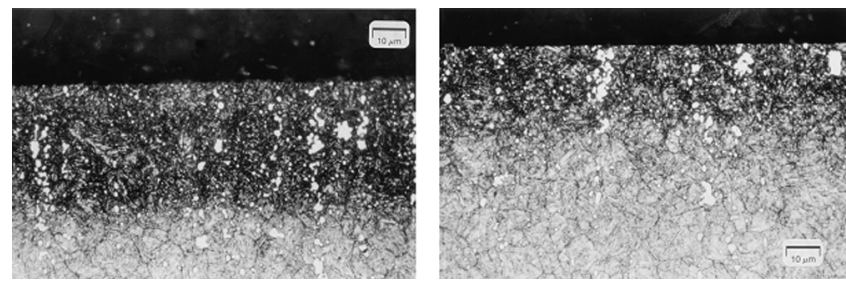

Fig. 4-Metallographic cross sections after 60 min nitriding time. Comparison of different load stresses during nitriding (left: bending stress of $754 \mathrm{MPa}$, right: bending stress of $-1050 \mathrm{MPa}) .{ }^{[32]}$

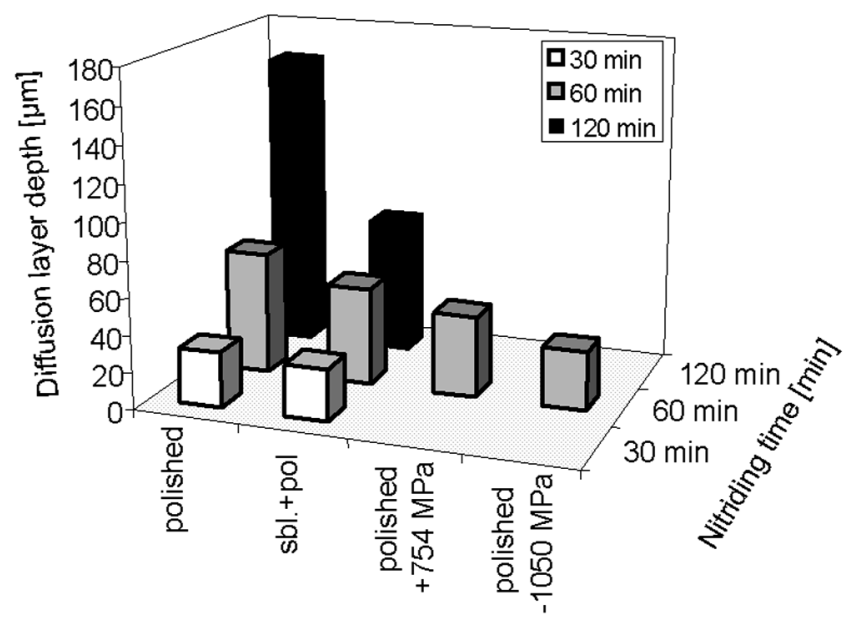

Fig. 5-Comparison of diffusion layer depths, measured at five different locations of metallographic cross sections.

A thicker layer can be observed, if plasma nitriding is done under tensile loads (Figure 4, left). Results of all nitrided samples are summarized in Figure 5. The diffusion layer thickness of polished samples increased from $30 \mu \mathrm{m}$ after 30 minutes to $160 \mu \mathrm{m}$ after 120 minutes nitriding time. For sand-blasted samples, only an increase from 28 to $74 \mu \mathrm{m}$ can be measured for similar treatment times. Diffusion layer thickness amounts to 32 and $44 \mu \mathrm{m}$ for samples nitrided for 60 minutes under compressive and tensile loads. Samples nitrided under load stresses altogether show smaller diffusion layers compared with samples containing residual stresses.

Figure 6 proved that no compound layer occurred during plasma nitriding at $500{ }^{\circ} \mathrm{C}$ using 5 vol pet $\mathrm{N}_{2}$ in $\mathrm{H}_{2}$ and 120 minutes nitriding time. Nitrided samples show additional diffraction lines belonging to chromium nitride. Diffraction lines of iron nitrides associated with white layer formation, however, 
could not be observed. Again, the phase analysis in Figure 6 supports the observation that white-layer-free plasma nitriding of high-speed steel M2 is possible.

For a further characterization of surface layers, element depth profiles of nitrogen and carbon are shown in Figures 7 through 9. For each nitriding time, Figure 7 demonstrates that samples with low values of residual stresses give higher penetration depths of nitrogen, compared to samples with high levels of residual stresses. This observation is marked by arrows, drawn from an imaginary line at $1 \mathrm{Ma}$ pct nitrogen content. Thus, the effect of different residual stress states on diffusion of nitrogen is obvious. This effect is more pronounced with increasing nitriding time. An interruption of the nitrogen depth profile for 120 minutes nitriding time is due to two subsequent measurements. At a surface distance of $60 \mu \mathrm{m}$, the first measurement was interrupted by short circuits. Following this, the sample was ground to this depth and a second measurement executed to higher surface distances. The diffusion layer

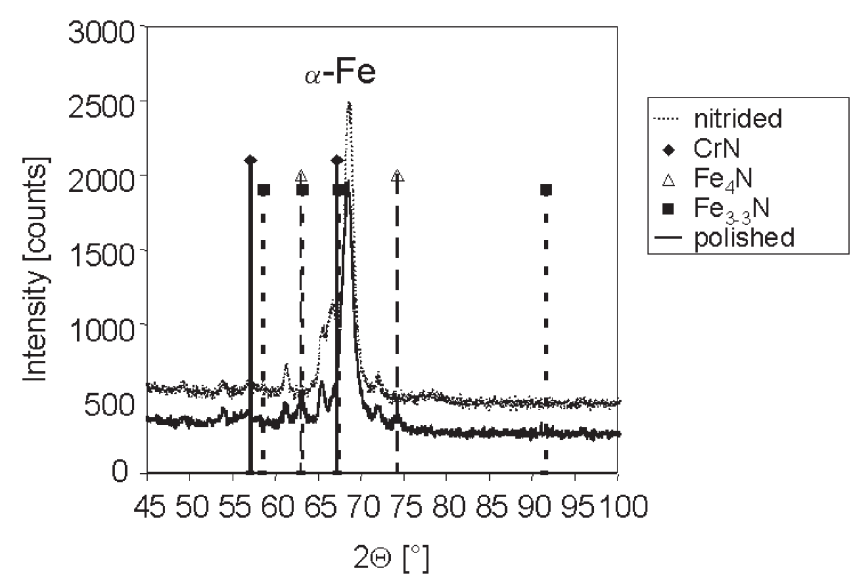

Fig. 6-Phase diagram ( $\mathrm{Cr} K_{\alpha}$ radiation) of as-delivered and nitrided specimens (nitrided at $500{ }^{\circ} \mathrm{C}$ for 120 min with 5 vol pct $\mathrm{N}_{2}$ ).

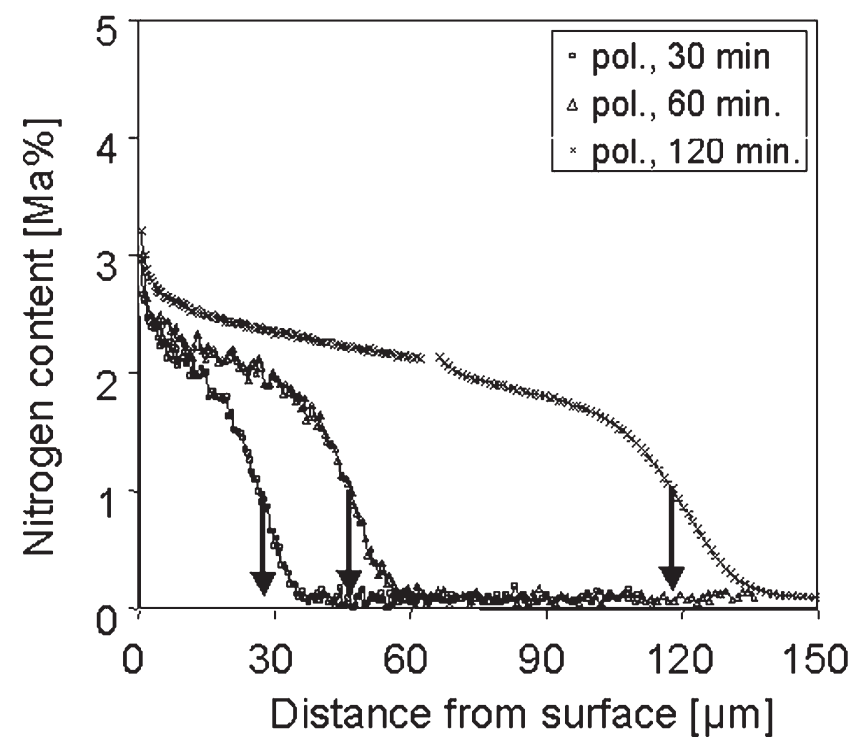

in this case proved to be particularly thick. Residual stress effects on diffusion must also be effective for the interstitial element carbon. Since a plasma nitriding atmosphere acts as a decarburizing medium, high values of compressive residual stresses will result in decreased levels of decarburization. This assumption is supported by the results in Figure 8. At the end of the diffusion layer, carbon contents are higher than the ones of the steel matrix. This is the result of an exchange between nitrogen and carbon and the high amount of phase boundaries formed by precipitates. It is somewhat easier for the carbon to diffuse into the core and precipitate as chromium carbides, instead of forming chromium-free cementite within the nitrided layer. ${ }^{[24,25]}$ Chromium carbides will react with nitrogen, allow-

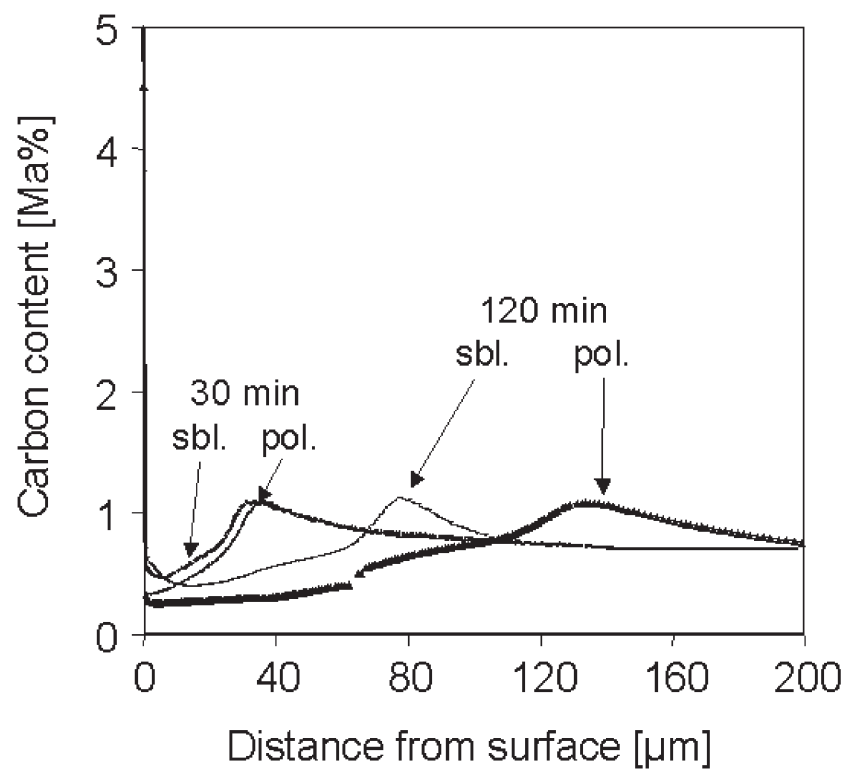

Fig. 8-GDOES depth profiles of carbon after 30 and 120 min nitriding time. Nitriding parameters: $T=500{ }^{\circ} \mathrm{C}, 5 \mathrm{mbar}, 5 \mathrm{vol}$ pet $\mathrm{N}_{2}$.

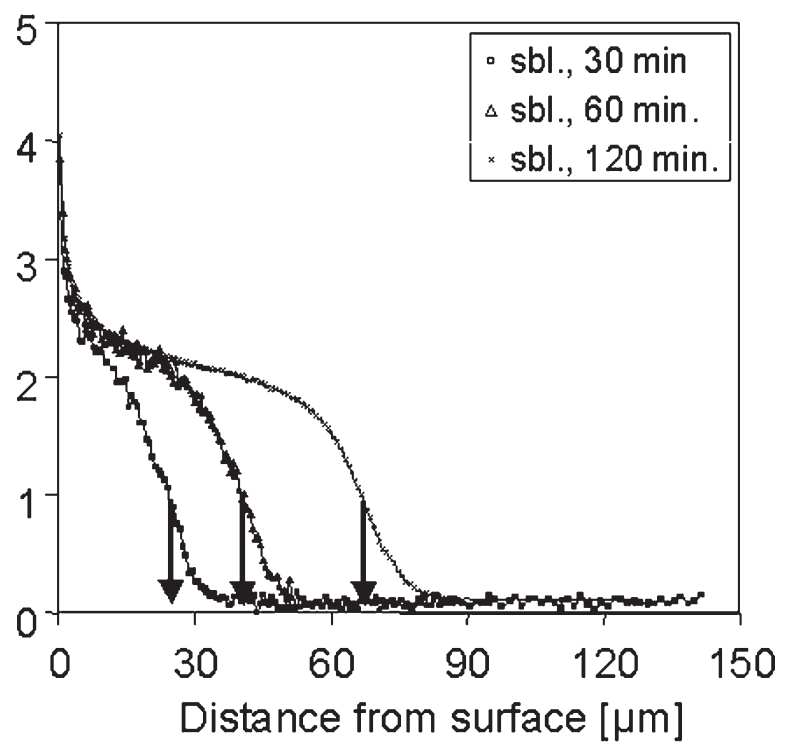

Fig. 7-GDOES depth profiles of nitrogen. Left: samples with low residual stress values. Right: samples with high residual stresses. Nitriding parameters: $T=500{ }^{\circ} \mathrm{C}, 5 \mathrm{mbar}, 5 \mathrm{vol}$ pct $\mathrm{N}_{2}$ different nitriding times (pol. = polished, sbl. = sand-blasted and polished). 


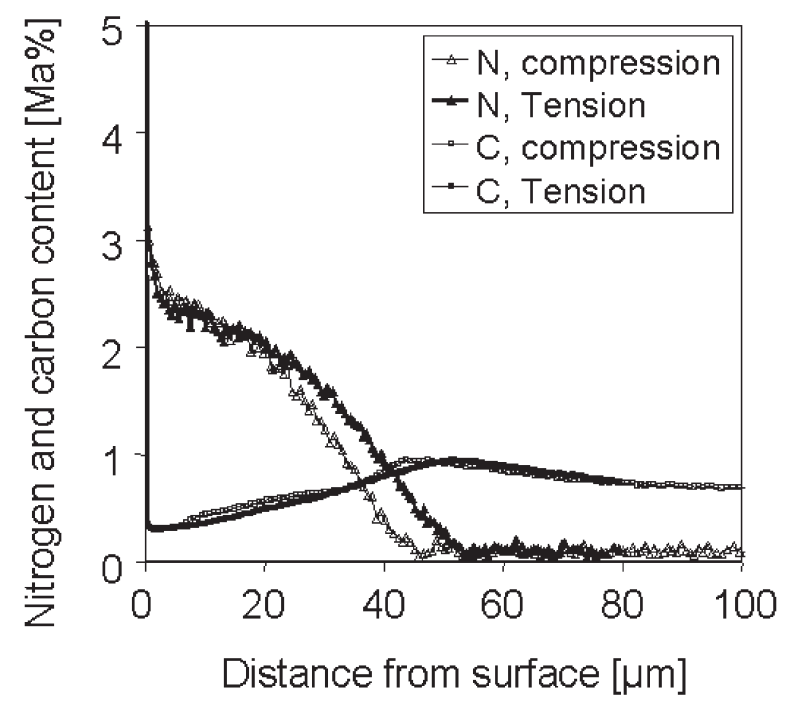

Fig. 9-GDOES depth profiles of nitrogen (triangles) and carbon (squares) after nitriding with load stresses (tension $=754 \mathrm{MPa}$, compression = $-1050 \mathrm{MPa}$ ). Nitriding parameters: $T=500{ }^{\circ} \mathrm{C}, 5 \mathrm{mbar}, 5$ vol pct $\mathrm{N}_{2}, 60$-min nitriding time.

ing carbon to diffuse to sites of lower chemical potential, forming a carbon-rich layer at the end of the diffusion layer. With increasing diffusion layer thickness, this maximum is shifted to higher distances from the surface. Generally, an increased nitriding time of 120 minutes would result in a larger decarburization (compare results for 30 and 120 minutes). With high values of compressive residual stresses, carbon diffusion is balked to some amount and higher carbon contents can be observed near the surface of the diffusion layer. The interruption of the carbon depth profile also results from an interruption of the measurement.

Figure 9 presents similar results of nitrogen and carbon depth profiles for samples nitrided under load stresses for 60 minutes. If again diffusion layer depths at 1 Ma pct nitrogen are taken for comparison, 12- $\mu \mathrm{m}$ thinner layers are observed for compressive loads, as already known from metallographic inspection. In contrast to the results in Figure 8, no significant difference in carbon contents could be found. It should be mentioned that only individual measurements have been done so far and experimental scatter has to be taken into account.

Depth profiles of residual stresses after plasma nitriding also are affected by operations prior to the plasma nitriding process, and material conditions which have been introduced. In Figure 10, the condition "sand-blasted" exhibits very high compressive surface residual stresses of $-1200 \mathrm{MPa}$ after nitriding for 30 minutes. These stresses increase to $-1600 \mathrm{MPa}$ at $10-\mu \mathrm{m}$ surface distance. Higher nitriding times result in a reduction of residual stress values for all surface distances, the residual stress maximum being shifted to higher surface distances. There is also a shift to higher depths with increasing nitriding time for the zero crossing of residual stresses, indicating the growing thickness of the diffusion layer. The polished surfaces, nitrided under load stresses, exhibit only slightly higher (lower) compressive residual stresses, if tensile (compressive) bending stresses have been applied. The depth profiles of residual stresses under the

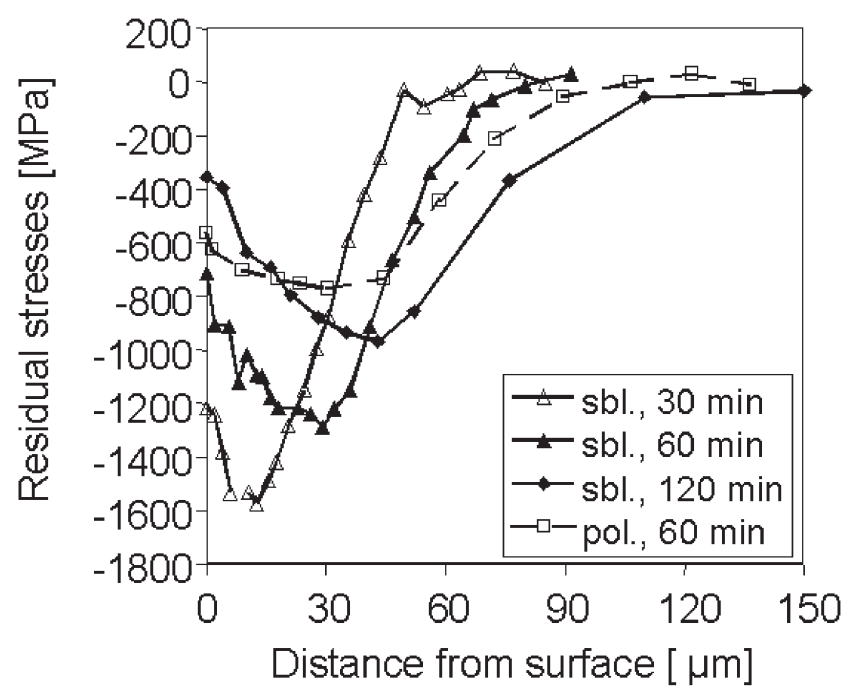

Fig. 10 - Depth profiles of residual stresses for polished, sand-blasted and polished samples nitrided at indicated times.

effect of load stresses basically correspond to those of polished samples without load stresses.

\section{DISCUSSION}

The present work contributes to the understanding of residual and load stress effects on the plasma nitriding response of high-alloyed tool steels. In earlier work, ${ }^{[5,6]}$ only low nitriding times of 30 minutes have been used and differences in nitrogen depth profiles of specimens with high and low compressive residual stresses could hardly be separated from experimental scatter. Nitrided samples without white layer have been obtained (Figures 3 through 5). A constant nitriding temperature of $500{ }^{\circ} \mathrm{C}$ was always used, so effects from temperature can be excluded in the discussion. A careful experimental preparation gave surface layers, which exhibited about 10 times different values of compressive residual stresses with similar surface topographies. In any case, surface layers with high compressive residual stresses resulted in thinner diffusion layers, the difference increasing with nitriding time. Further attempts to establish quantitative data were made by nitriding samples under compressive and tensile bending load stresses. On first sight, these experiments led to comparable results as received from different residual stress levels. Hydrostatic parts of load stress tensors can be derived from the bending tests and correlated to effects on diffusion coefficients.

Generally, the following changes in material states contribute to the generation of residual stresses during nitriding: ${ }^{[10,11,12]}$

(1) changes of chemical composition in the diffusion layer;

(2) formation of precipitates and changes in chemical composition, density, and distribution of these precipitates in the diffusion layer;

(3) volume effects by incorporation of foreign atoms or the formation of chemical compounds;

(4) the different thermal coefficients of expansion between nitride phases and the ferritic matrix during cooling; and (5) residual stress fields around lattice defects. 
If no relaxation of machining-induced residual stresses occurs, nitriding-induced residual stresses will be superimposed on machining-induced residual stresses or at least be affected by these.

High hydrostatic pressures in low-strength materials result in an increase of the activation energy for diffusion and thus to a decrease of the diffusion coefficient. ${ }^{[16,17]}$ Stress-induced diffusion is a preferential diffusion of solved interstitials in a direction perpendicular to the applied tensile stress. ${ }^{[17]}$ Perpendicular to the applied tensile stress, lattice contractions favor atom movements. The case described for load stresses also should apply to macroscopic residual stress. Compressive residual stresses act parallel to the surface and decrease the distances of the solved atoms in this direction. Accordingly, compressive residual stresses facilitate nitrogen diffusion parallel to the surface and obstruct a diffusion perpendicular to it, resulting in thinner diffusion layers. A different thickness of diffusion layers can be expected from different load or residual stresses and was verified experimentally by the given results.

For a semiquantitative analysis of load stress effects on diffusion, a procedure given in Reference 26 will be followed. Reference 26 describes effects of hydrostatic pressure on diffusion. The general equation for diffusion is partially differentiated in terms of pressure for constant temperature and results in Eq. [1]:

$$
\begin{array}{r}
\left(\frac{\partial \ln D}{\partial p}\right)_{T}=-\frac{\Delta V}{\mathrm{k} T}+\left(\frac{\partial \ln a^{2}}{\partial p}\right)_{T}+\left(\frac{\partial \ln \widetilde{\nu}}{\partial p}\right)_{T} \text { with } \\
\left(\frac{\partial \ln a^{2}}{\partial p}\right)_{T}=0 \text { and }\left(\frac{\partial \ln \widetilde{\nu}}{\partial p}\right)=\gamma \cdot \kappa
\end{array}
$$

The two-dimensional elements $a$, from which the diffusion coefficient is determined, exhibit no pressure dependence and the dependence of the jump frequency $\nu$ on the pressure can be described by the Grüneisen parameter $\gamma$ and the isothermal compressibility $\kappa$. The term $\Delta V$ is the activation volume for diffusion, $D$ the diffusion coefficient, $p$ the hydrostatic pressure, and $\mathrm{k}$ the Boltzmann constant. If the partial derivatives are seen as finite differences, Eq. [2] results after simple transformation:

$$
\begin{gathered}
\Delta D=\exp \left[\left(-\frac{\Delta V}{\mathrm{k} T}+\gamma \cdot \chi\right) \cdot \Delta p\right]_{T} \quad \text { resp. } \\
\Delta D=\exp \left[\left(-\frac{\Delta V}{\mathrm{k} T}+\gamma \cdot \chi\right) \cdot \sigma_{H}\right]_{T}
\end{gathered}
$$

Problems arise regarding correct data for activation volumes of nitrogen or carbon diffusion in iron. Reference 27 describes these values to be very small at low temperatures $(\sim 6$. $\left.10^{-23} \mathrm{~mm}^{3}\right)$. The activation volume data close to the transformation temperature $\alpha-\mathrm{Fe} / \gamma \mathrm{Fe}$ is given as $2.37 \cdot 10^{-20} \mathrm{~mm}^{3}$. ${ }^{[28]}$ By linear interpolation of these literature data, a value for the nitriding temperature of $500{ }^{\circ} \mathrm{C}$ was estimated to 1.39 . $10^{-20} \mathrm{~mm}^{3}$. This value in spite of different processes is similar to recent results for self-diffusion of iron in an iron-silicon alloy $\left(1.48 \cdot 10^{-20} \mathrm{~mm}^{3}\right) .{ }^{[29]}$ With the Boltzmann constant, an average value for the Grüneisen parameter of $1.81,{ }^{[30,31]}$ and the isothermal compressibility of $6.69 \cdot 10^{-6} \mathrm{~mm}^{2} / \mathrm{N}$, the effect of hydrostatic pressure on diffusion can be estimated and is represented in Figure 11. The hydrostatic part of the stress

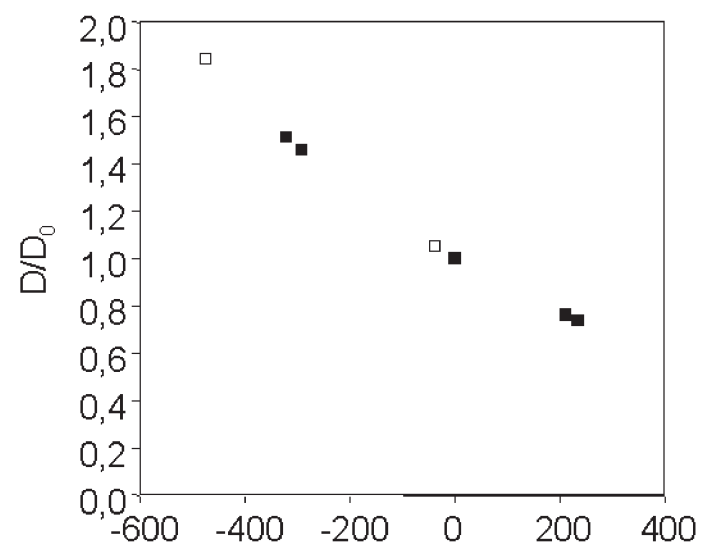

Hydrostatic part of stress / residual stress tensor [MPa]

Fig. 11-Calculated differences in the diffusion coefficient, plotted against the hydrostatic part of the load stress tensor (black squares) and residual stress tensor (white squares).

tensor (main stresses $\sigma_{i}$ or residual stresses $\sigma_{i}^{E S}$ ) was calculated with Eq. [3]:

$$
\begin{aligned}
& \sigma_{H}=\frac{1}{3}\left(\sigma_{1}+\sigma_{2}+\sigma_{3}\right) \quad \text { or } \\
& \sigma_{H}=\frac{1}{3}\left(\sigma_{1}^{E S}+\sigma_{2}^{E S}+\sigma_{3}^{E S}\right)
\end{aligned}
$$

In Figure 11, the plot of diffusion coefficients against all experimental values of load and residual stresses is linear. ${ }^{[27]}$ For maximum load stress differences of $1700 \mathrm{MPa}$, a factor of 1.977 can be estimated. This factor for residual stress differences of $1500 \mathrm{MPa}$ is as high as 1.84 . So far, maximum differences in the diffusion coefficients can be expected to be about a factor of 2 .

An estimate of stress or residual stress-induced differences in nitrogen depth profiles now can be computed from Figure 11 via Eq. [4], if correct data for the diffusion of nitrogen in an M2 tool steel is available. It should be clear that this diffusion coefficient is lower than data known, e.g., for low-carbon steels $\left(D\right.$ at $T=500{ }^{\circ} \mathrm{C}, \sigma_{h}=0$ is $1.808 \cdot$ $\left.10^{-7} \mathrm{~cm}^{2} / \mathrm{s}^{[32]}\right)$. Literature data from ion-implated M2 steel gives $3.8 \cdot 10^{-10} \mathrm{~cm}^{2} / \mathrm{s}^{[33]}$ and $8.7 \cdot 10^{-10} \mathrm{~cm}^{2} / \mathrm{s}$. ${ }^{[34]}$ These values are indeed a factor of 1000 lower than diffusion coefficients for low- and medium-carbon steels. Calculations from the GDOES data in Figure 7 resulted in values of 7.2 . $10^{-9} \mathrm{~cm}^{2} / \mathrm{s}$ for polished samples plasma nitrided at $500{ }^{\circ} \mathrm{C}$ for 2 hours. ${ }^{[32]}$ The increase by a factor of 10 , compared to ion implantation, ${ }^{[33,34]}$ can be understood from the higher temperature applied with plasma nitriding and generally from the different processes. Using $D\left(T=500{ }^{\circ} \mathrm{C}, \sigma_{h}=0\right)=$ $7.2 \cdot 10^{-9} \mathrm{~cm}^{2} / \mathrm{s}, c_{k}=0.1 \mathrm{Ma}$ pct $\mathrm{N}, c_{0}=3 \mathrm{Ma}$ pct $\mathrm{N}$ in Eq. [4] and effects from load and residual stresses, nitrogen depth profiles can be computed and differences be compared for a constant level of nitrogen (here for example for 0.1 Ma pct $\mathrm{N}$ ).

$$
c(x)=c_{0}-\left(c_{0}-c_{k}\right) \operatorname{erf} \frac{x}{\sqrt{D\left(\sigma_{H}\right) \cdot t}}
$$

where $c(x)$ is the nitrogen concentration plotted against depth $x, c_{0}$ the surface nitrogen concentration taken from GDOES 
depth profiles, $c_{K}$ the nitrogen concentration in the core, $D\left(\sigma_{H}\right)$ the stress-affected diffusion coefficient, and $t$ the nitriding time. Results are plotted in Figure 12 together with experimental data from metallographic inspection. After 120 minutes nitriding time, the calculation results in differences of $78 \mu \mathrm{m}$ for computed values compared to an experimental value of $88 \mu \mathrm{m}$. This correlation is acceptable. Calculated data for 60 minutes nitriding time, however, overestimate experimental data by a factor of 4 . Good correlation is found, if the diffusion coefficient is decreased by a factor of about 10, as indicated in Figure 12. This time dependence of the diffusion coefficient might be caused by the fact that nitrogen diffusion is affected by a chemical interaction with alloying elements (generation of $\mathrm{Cr}_{2} \mathrm{~N}$ or $\mathrm{CrN}, \mathrm{VN}$ precipitations) and a related increase in activation enthalpy in accordance with a decrease in diffusion coefficients. However, further work is necessary to clarify these facts in detail.

Differences in residual stress depth profiles (Figure 10) might be considered as well as a complex interaction of stress-affected precipitation of chromium nitrides, an exchange of carbon against nitrogen in carbides, and, additionally, a decarburization of near surface layers. The increase of carbon contents at the end of the diffusion layer, together with factors already mentioned, may contribute to residual stress states after plasma nitriding of a high-speed steel. Changes of residual stress states, seen in Figure 10, are known from chromium-alloyed nitriding steels, ${ }^{[10,12]}$ and are described by an increasing decarburization of near surface layers. However, clear differences between nitriding residual stresses of polished and sand-blasted samples additionally occur. Plastic deformation attributed to sand blasting prior to nitriding led to an extended amount of nitride precipitates and to higher values of compressive residual stresses in thicker layers. These results can be proven metallographically by higher precipitate densities in surface layers of sand-blasted samples. Increasing nitriding time will result in a growth of fine nitride precipitations or a transition from

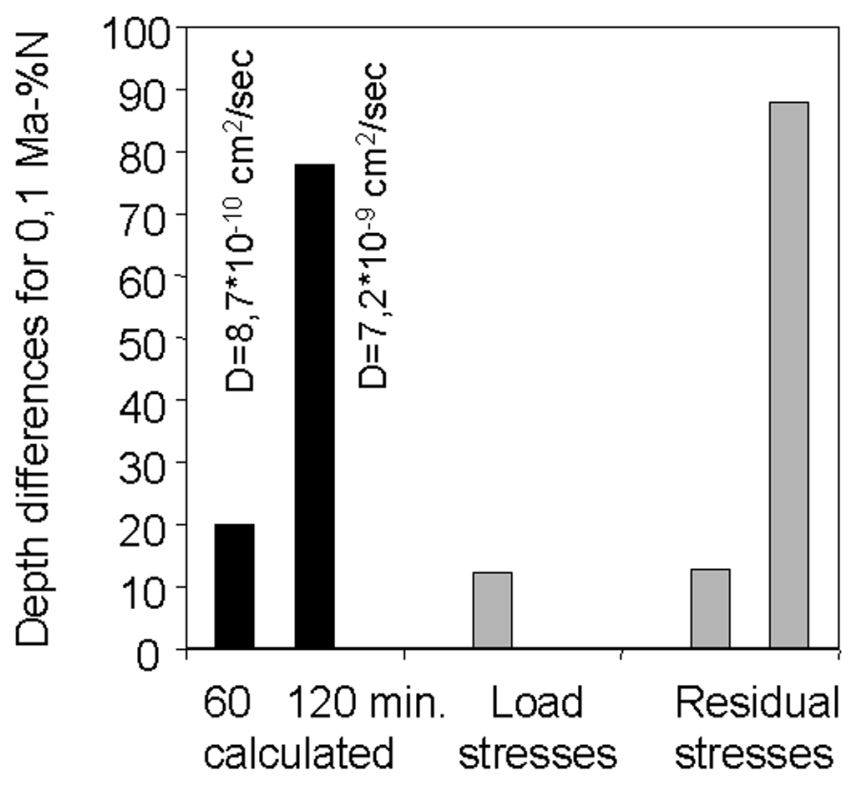

Fig. 12-Differences in depth at $0.1 \mathrm{Ma}$ pct nitrogen for different levels of load and residual stresses (black columns: calculated data, gray columns: experimental data).
$\mathrm{Cr}_{2} \mathrm{~N}$ to $\mathrm{CrN}$ precipitates. Compressive residual stresses first of all favor the formation of $\mathrm{Cr}_{2} \mathrm{~N}$ due to the smaller volume increase. ${ }^{[35,12]}$ There is also a somewhat minor decarburization in sand-blasted samples (Figure 6). Generally, higher nitriding residual stresses compared to polished surface states are expected from a reduced decarburization. The comparison of nitriding residual stresses plasma nitrided under the effect of load stresses gives a small effect only, if compared to unloaded samples. Whereas residual stresses in principle are produced by a change in material surface states, load stresses do not affect the material state; this result was to be expected.

\section{CONCLUSIONS}

The following conclusions can be drawn from this work.

As expected, mechanical polishing and sand-blasting resulted in different surface layer properties with a factor of 10 different compressive residual stress values. By a soft additional polishing of sand-blasted samples, additionally, similar surface topographies were present for all samples.

A following plasma nitriding treatment, executed at $500{ }^{\circ} \mathrm{C}$ with a gas mixture of 5 vol pct $\mathrm{N}_{2}$ in hydrogen, resulted in white-layer-free surface layers. Surface layers with high compressive residual stresses prior to nitriding exhibited thinner diffusion layers compared to samples with almost zero levels of residual stresses. Similar effects can be observed for compressive load stresses.

Linear plots of the diffusion coefficient result, if stressaffected differences of this coefficient are plotted as a function of the hydrostatic part of load or residual stress tensor. Calculations of stress-affected depth profiles of nitrogen show acceptable correlation with experimental results. Diffusion coefficients in general are far lower compared to low-alloyed steels. Nitrogen diffusion in high-alloyed steels is also affected by a chemical interaction with alloying elements (generation of $\mathrm{Cr}_{2} \mathrm{~N}$ or $\mathrm{CrN}$, $\mathrm{VN}$ precipitations) and an increase in activation enthalpy in accordance with a decrease in diffusion coefficients.

\section{REFERENCES}

1. J.R. Davis: ASM Handbook, 10th ed., ASM, Metals Park, OH, 1991, vol. 4, pp. 420-24.

2. R. Grün and H.J. Günther: Mater. Sci. Eng., 1991, vol. A140, pp. 435-41.

3. B. Edenhofer and T.J. Bewley: Heat Treatment, 1976, vol. 9, pp. 7-13.

4. D. Günther, T. Hirsch, F. Hoffmann, and P. Mayr: Härterei-Technische Mitteilungen, 1998, vol. 53, pp. 203-10.

5. A. da Silva Rocha, T.R. Strohaecker, V. Tomala, and T. Hirsch: Surface Coatings Technol., 1999, vol. 115, pp. 24-31.

6. A. da Silva Rocha, T.R. Strohaecker, and T. Hirsch: Surface Coatings Technol., 2003, vol. 165, pp. 176-85.

7. S.R. Bradbury, D.B. Lewis, and M. Sarwar: Surface Coatings Technol., 1996, vol. 85, pp. 215-20.

8. D.B. Lewis, S.R. Bradbury, and M. Sarwar: Surface Coatings Technol., 1996, vol. 82, pp. 187-92.

9. E.J. Mittemeijer and M.A.J. Somers: Härterei Technische Mitteilungen, 1992, vol. 47, pp.175-82.

10. H. Oettel and G. Schreiber: AWT-Tagungsband "Nitrieren und Nitrocarburieren," AWT, Wiesbaden, Germany, 1991, pp. 139-51.

11. U. Kreft, F. Hoffmann, T. Hirsch, and P. Mayr: in Surface Modification Technologies VIII, T.S. Sudarshan and M. Jeandin, The Institute of Materials, London, 1995, pp. 148-60.

12. D. Günther, F. Hoffmann, and T. Hirsch: Härterei-Technische Mitteilungen, 2003, vol. 58, pp. 64-73.

13. J.F. Gu, D.H. Bei, J.S. Pan, J. Lu, and K. Lu: Mater. Lett., 2002, vol. 55 , pp. $340-43$. 
14. H. Ferkel, M. Glatzer, Y. Estrin, and R.Z. Valiev: Scripta Mater., 2002, vol. 46, pp. 623-28.

15. F. Hoffmann: Ph.D. Thesis, University of Bremen, Bremen, Germany.

16. R.E. Smallman: Modern Physical Metallurgy, 2nd ed., Butterworth and Co., London 1963, pp. 111-12.

17. R.E. Reed-Hill: Physical Metallurgy Principles, 2nd ed., PWS-Kent Publ. Co., Boston, MA, 1992, pp. 433-42.

18. P.M. Unterweiser: Heat Treaters Guide: Practices and Procedures for Irons and Steels, 2nd ed. ASM, Metals Park, OH, 1989, p. 904.

19. F. Dornelles Ramos: Master's Thesis, UFRGS, Porto Alegre, Brazil, 2003.

20. E. Rose and P. Mayr: Mikrochim. Acta, 1989, vol. I, pp. 197-212.

21. Z. Weiss and K. Marshall: Thin Solid Films, 1997, vols. 308-309, pp. 382-88.

22. V. Hauk: Structural and Residual Stress Analysis by Nondestructive Methods: Evaluation, Application, Assessment, Elsevier, Amsterdam, 1997, pp. 388-92.

23. H.C.F. Rozendaal: Ph.D. Thesis, University of Delft, Delft, The Netherlands, 1985.

24. S. Mridha and D. Jack: Met. Sci., 1982, vol. 16, pp. S.398-S.404.

25. D. Scott: Treatise on Materials Science and Technology, vol. 13, Wear, Academic Press, New York, NY, 1979, pp. 449-51.
26. J. Philibert: Les Editions de Physique, Les Ulis, Cedex A, France, 1991, p. 110.

27. A. Köthe and F. Schlät: Diffusion in Metallischen Werkstoffen, VEB Verlag, Leipzig, 1970, p. 116.

28. C.G. Homan and J.F. Cox: in Physics and Solids at High Compressives, C.T. Tomizuka and R.M. Emrick, eds., Academic Press, London, 1965, pp. 374-77.

29. A. Gude, K. Freitag, B. Sepiol, G. Vogl, and H. Mehrer: Physica Status Solidi B-Basic Res., 1996, vol. 197, pp. 299-307.

30. J.K. Baria, P.N. Gajjar, and A.R. Jani: on-line paper 20, Sept. 2003, via http://fizika.hfd.hr/fizika a/av03/a12p023.pdf

31. L.S. Dubrovinsky, S.K. Saxena, N.A. Dubrovinskaia, and T. LeBihan: Am. Mineralogist, 2000, vol. 85, pp. 386-89.

32. H. Klümper-Westkamp: Ph.D. Thesis, University of Bremen, Bremen, Germany, 1989

33. P.J. Wilbur, J.A. Davis, R. Wie, J.J. Vaja, and D.L. Williamson: Surface Coatings Technol., 1996, vol. 83, pp. 250-56.

34. R. Trejo-Luna, L. Cota, L. Martinez, L. Morales, and J. Richards: Scripta Metall., 1985, vol. 19, pp. 1297-1300.

35. E.J. Mittemeijer: Härterei Technische Mitteilungen, 1981, vol. 36, pp. $45-70$. 